\title{
The Study of Collapsible for Intact Loess and Remolded Loess
}

\author{
Kangfeng Yuan ${ }^{\mathrm{a}}$ \\ (a, Key Lab of Highway Construction \& Maintenance Technology in Loess Region, Ministry of Transport, PRC, \\ b, Shanxi Key Laboratory of Highway Construction \& Maintenance Technology \\ in Loess Region,Shanxi Transportation Research Institute, Shanxi, Taiyuan 030006, China) \\ ayuankangfeng@163.com
}

\begin{abstract}
At present, there are not enough research for the intact loess and remolded loess collapsible; There are tests for the some region loess, to study the law of collapsible.The results showed that: The curve of intact loess and remolded loess collapsible deformation is defined by two turning points and three segments. The collapsible coefficient of intact loess is bigger than remolded loess collapsible coefficient for each region loess. The collapsible coefficient of jishan loess is greatest.Than the collapsible coefficient of shouyang loess is least for the same conditions.
\end{abstract}

Keywords-collapsible; intact loess; greatest; remolded loess; region

\section{INTRODUCTION}

The collapsible loess is widely distributed in our country. The research shows that: the collapsibility can be attributed to internal factor and external factor. Internal factor is the composed structure of loess.External factors are the load and water of loess. Wang Ji-qing[1] think that there is good relation among loess collapsibility coefficient, water content, dry density, void ratio and compressive modulus. Li Yu-nong [2] think that as the depth increases, the collapsibility coefficient reduces; the water content and dry density are negatively correlated with the collapsibility coefficient. A linear equation between collapsibility coefficient of loess and its main influential factors have been established through regression analysis.Jing Yan-lin[3] think that coefficient of collapsibility is closely correlated to the compaction rate, but significantly in negative correlation with the collapsibility coefficients. The study of collapsible for intact loess and remolded loess have some theoretical value [4]-[26]. The relation study of collapsible is the most important task for the survey of loess.

The loess of tests come from the foundation pit of some district. And to quantitatively investigate the loess collapsible of intact loess and remolded loess. And get some conclusion which is a new attempt for the study of collapsible theoretical.

\section{THE LOESS OF TEST}

The loess of tests is taken from certain foundation pit at the some district,which is silty clay, with a small amount of worm holes. The loess samples have been whittled to length $27 \mathrm{~cm} \sim 30 \mathrm{~cm}$ cube in the field, with the plastic wrapped well and indicated the vertical direction, transported back to the laboratory.

The undisturbed samples is taken from the depth of $1.7 \mathrm{~m}$. The natural moisture content of loess samples is $9.5 \% \sim 12 \%$. The average dry density is $1.53 \mathrm{~g} / \mathrm{cm} 3$.

\section{TeST InstrumENTS AND TEST METHOD}

\section{A Test Instruments}

The test instrument is the conventional leveraged compression apparatus which come from a Nanjing experimental instrument factory.According to the specific requirement of the test.The pressurized equipment is adjusted.

\section{B Test Method}

The collapsible test use the method of single. The samples are installed in the compression apparatus, the vertical pressure is applied to compress. And the vertical pressure are $50 \mathrm{kPa}, 100 \mathrm{kPa}, 200 \mathrm{kPa}, 400 \mathrm{kPa}, 800 \mathrm{kPa}$. When the compression stabilized, to water for saturation, until the deformation stabilized.

\section{4. TEST RESULTS AND ANALYSIS}

The curve of loess collapsible deformation for each region loess is indicated in Fig .1 to 6:

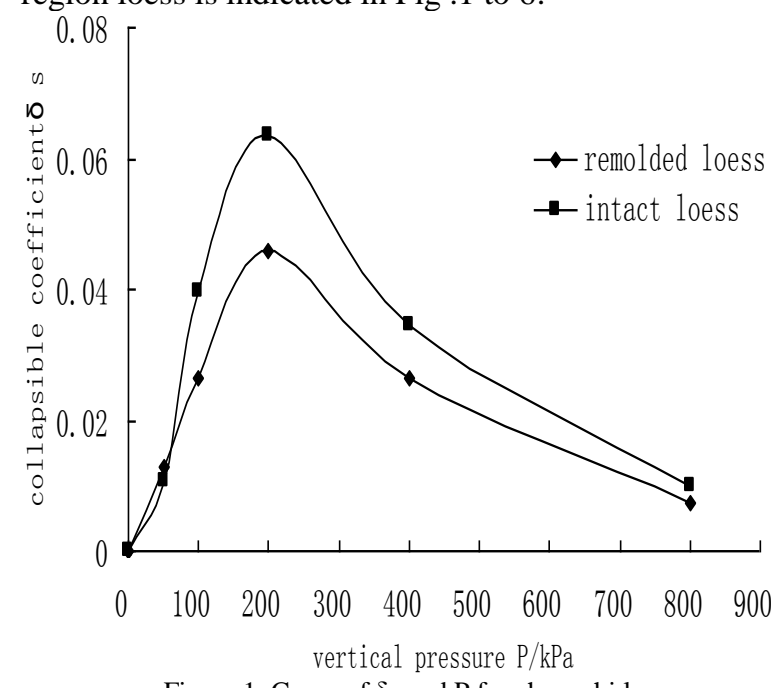

Figure 1. Curve of $\delta$ s and $\mathrm{P}$ for changzhi loess 


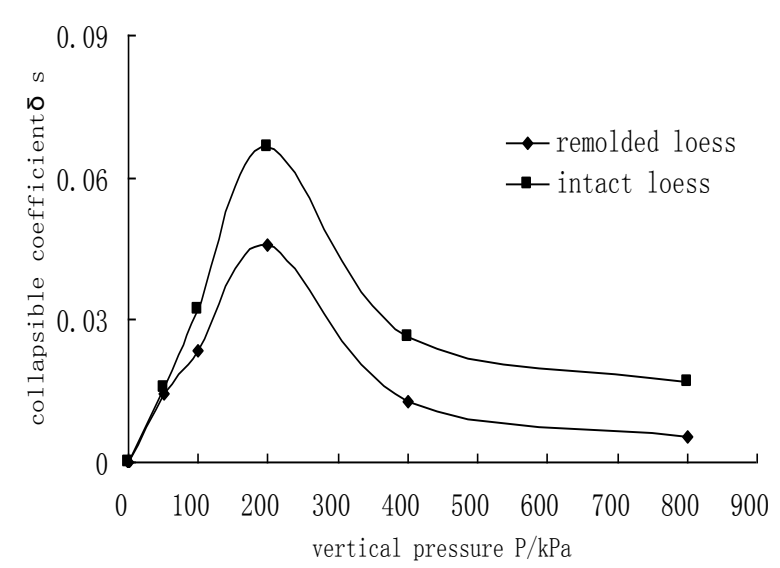

Figure 2. Curve of $\delta$ s and $\mathrm{P}$ for yangcheng loess

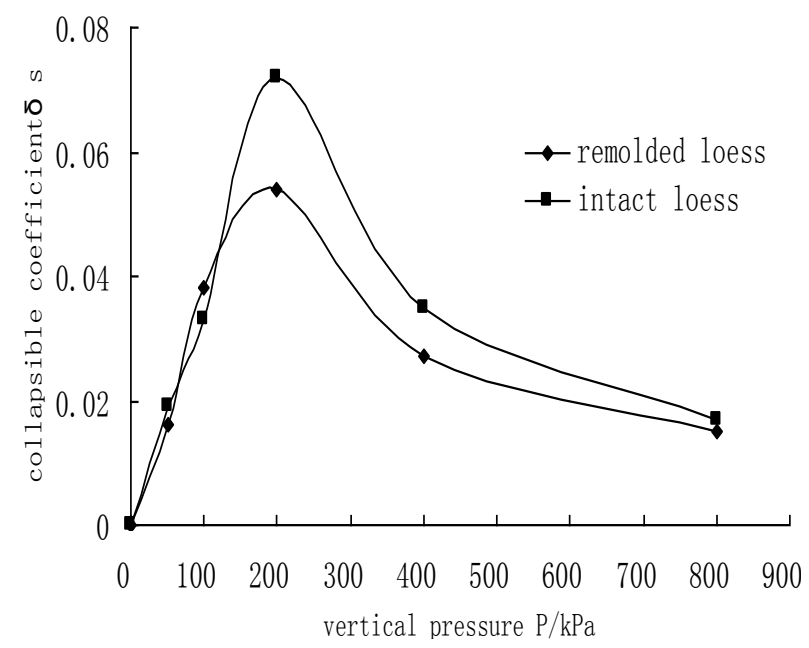

Figure 3. Curve of $\delta \mathrm{s}$ and $\mathrm{P}$ for linyi loess

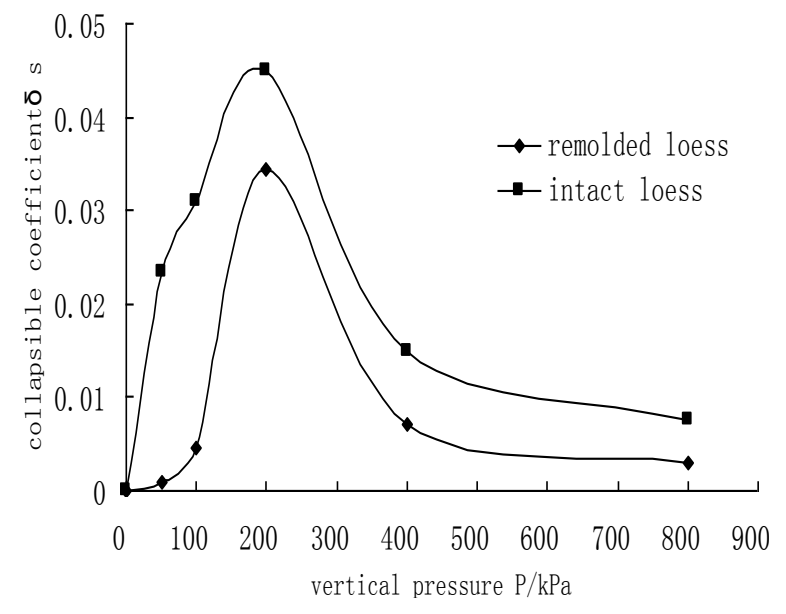

Figure 4. Curve of $\delta \mathrm{s}$ and $\mathrm{P}$ for shouyang loess

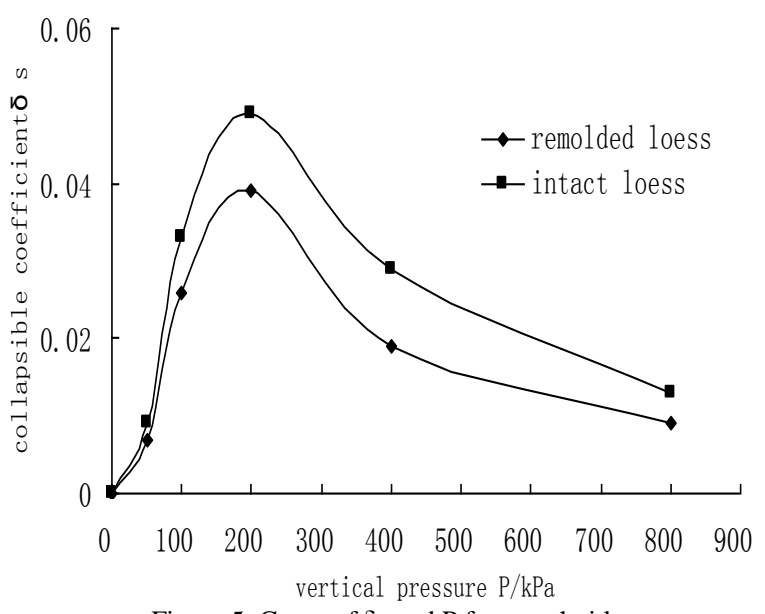

Figure 5. Curve of $\delta s$ and $\mathrm{P}$ for wenshui loess

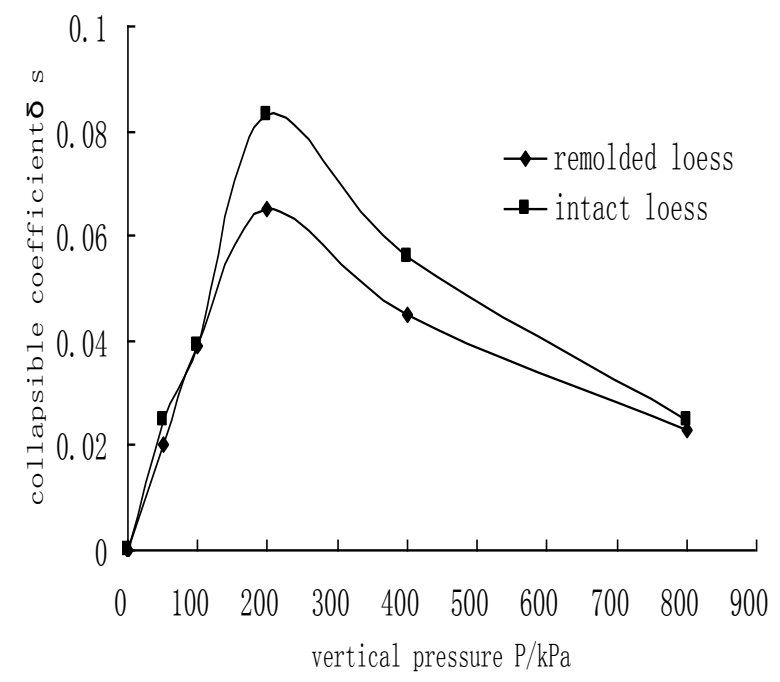

Figure 6. Curve of $\delta$ s and $\mathrm{P}$ for jishan loess

Fig .1-6 shows that the curve of intact loess and remolded loess collapsible deformation is defined by two turning points and three segments. The front of first turning point is the structural compaction phase. The interval of two turning points is the stage of structural damage. The after of second turning point is the new structure formation phase. And the development of three stages change with the role of pressure.

Fig .1-6 shows that the collapsible coefficient of intact loess is bigger than remolded loess collapsible coefficient for each region loess.

Fig .7 and Fig .8 show that the curve of intact loess and remolded loess collapsible for some region loess. 


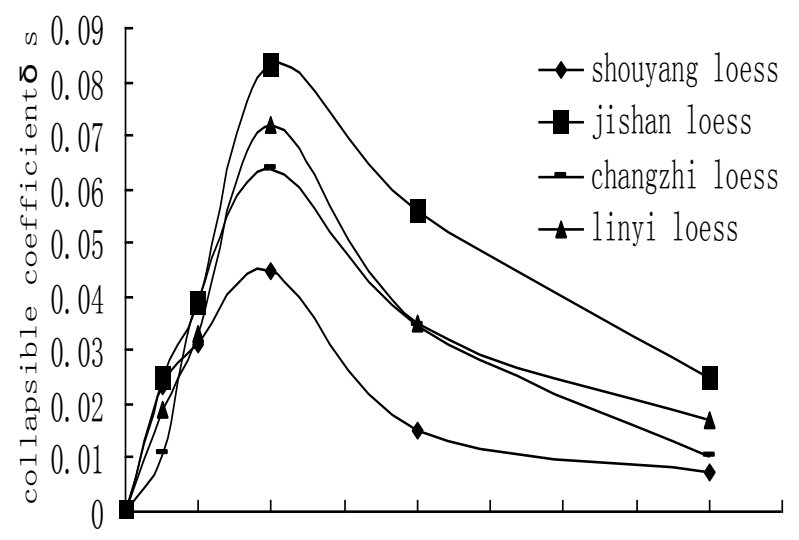

$\begin{array}{llllllllll}0 & 100 & 200 & 300 & 400 & 500 & 600 & 700 & 800 & 900\end{array}$

vertical pressure $\mathrm{P} / \mathrm{kPa}$

Figure 7. Curve of $\delta$ s and $\mathrm{P}$ for intact loess

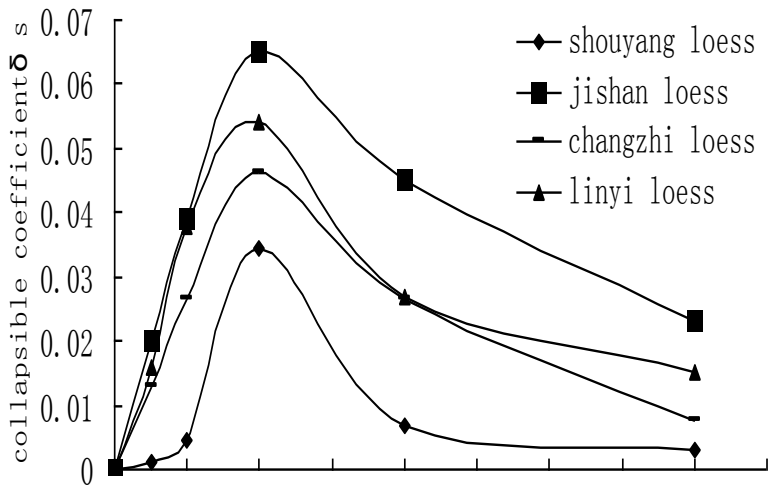

$\begin{array}{llllllllll}0 & 100 & 200 & 300 & 400 & 500 & 600 & 700 & 800 & 900\end{array}$

vertical pressure $\mathrm{P} / \mathrm{kPa}$

Figure 8. Curve of $\delta$ s and $\mathrm{P}$ for remolded loess

Fig .7, Fig .8 show that the collapsible coefficient of jishan loess is greatest for the same conditions. Than the collapsible coefficient of shouyang loess is least for the same conditions.

\section{CONCLUSIONS}

In the paper, the author try to study the regular of collapsible coefficient for some region loess. The main conclusions are as follows:

(1) The curve of intact loess and remolded loess collapsible deformation is defined by two turning points and three segments.

(2) The collapsible coefficient of intact loess is bigger than remolded loess collapsible coefficient for each region loess.

(3) The collapsible coefficient of jishan loess is greatest for the same conditions.Than the collapsible coefficient of shouyang loess is least for the same conditions..

\section{ACKNOWLEDGEMENTS}

The paper is Sponsored by the Research Project of Shanxi Provincial Communication Department [2012-1-3].

\section{REFERENCES}

[1] Jiqing Wang, Shengyou Lei,Xiaolun Li,et al. Correlation of wet collapsibility coefficient and physical property parameters of loess[J]. COAL GEOLOGY \& EXPLORATION, 2013, 41(3): 42-45 (In Chinese)

[2] Yunong Li. Analysis on factors affecting collapsibility coefficient of loess $[\mathrm{J}]$. GLOBAL GEOLOGY, 2007,26(1):108-113 (In Chinese).

[3] Yanlin Jing, Yanqing Wu,Dujun Lin,et al.Study of relationship between loess collapsibility and index of compaction test[J].Rock and Soil Mechanics, 2011,32(2):393-397 (In Chinese) .

[4] Wankui Ni, Bin Yan, Haisong Liu. Evaluation of collapsible loess subgrade along expressway $[\mathrm{J}]$. Journal of Engineering Geology, 2007,15(4):513-520 (In Chinese).

[5] Jiping Wang. The application of loess collapisible initial pressure to the engineering [J].SHANXI SCIENCE \& TECHNOLOGY of COMMUNICATIONS, 2004 2004(1):23-24 (In Chinese).

[6] Xinwen Gao.Collapsible loess foundation disposal study [J]. SHANXI SCIENCE \& TECHNOLOGY of COMMUNICATIONS, 2008,190(1):7-9 (In Chinese)

[7] Barden L.Pavlakis G.Air and water permeability of compacted unsaturated cohesive soil[J].Journal of Soil Society, 1971,23(3):302-317.

[8] XIONG Chuan-xiang, GONG Xiao-nan. An updated elastoplastic damage model for structural soft-clays[J].Rock and Soil Mechanics, 2006, 27(3): 395 - 397.(in Chinese)

[9] SHEN Zhu-jiang, LIU En-long, CHEN Tie-lin. Generalized Stress-Strain Relationship of Binary Medium Model for Geological Materials[J]. Chinese Journal of Geotechnical Engineering, 2005,27(5):489-494.(in Chinese)

[10] Zhu Si-zhe,Liu Qian,Chang Ya-ping,et al.The principles and Applications Technology of Triaxial Tests[M] .2003, China Electric Power Press. (in Chinese)

[11] Fredlund D G,Morgenstern N R.Stress state variables for unsaturated soils[J].Journal of the Engineering Division,ASCE, 1997,103(GT5):477-466.

[12] WANG Li-zhong, ZHAO Zhi-yuan, LI Ling-ling.Non-linear elastic model considering soil structural damage[J]. Journal of Hydraulic Engineering, 2004, (1):83-89.(in Chinese)

[13] Khalili N.and Khabbaz M.H,An Effective Stress Based Approach for Shear Strength Determination of Unsaturated Soil,Proceedings of the Second International Conference on Unsaturated Soils,Beijing,1998.8,Vol.2,pp.84-89.

[14] Khalili N.and Khabbaz M.H,On the Theory of Three-dimensional Consolidation in Unsaturated Soil, Proceedings of the First International Conference on Unsaturated Soils,Paris,1995,Vol.2,pp.745-750.

[15] Rohm S A,Vilar O M..Shear strength of unsaturated sandy soil[A].Proc.1st . Int.Conf. Unsaturated Soils[C].Paris. [s.n.].1995,189-195.

[16] Jennnigs J E.A revised effective stress law for use in the prediction of behavior about unsaturated soils[A].Poreeeding of Pore Pressure and Suction in soils[C], London, U.K., 1961, 26-30.

[17] Artehsor G D.Relationship of moisture stress and effective stress function in unsaturated soils[A].Proeeeding of Pore Pressure and Suction in soils[C], London, U.K., 1961, 47-52.

[18] Bishop A W, Blight G E.Some aspects of effective srtess in suatrated and partly saturated soils[J].Geotechnique, 1963 (13)3:177-196

[19] Bishop W.The principle of effective srtess[J].Teknisk Ukeblad, 1959, 106(39):859-863.

[20] J.K-M.Can and D.G.Fredlund,Shear Strength Characteristics of Two Saprolitic Soils from Hong Kong,Sino-Canadian Symposium on Unsaturated/Expansive Soils, Wuhan, June.1994. 
[21] S.K.Vanapalli,D.G.Fredlund D.E.Pufahl and A.W.Clifton,Model for the Predicition of Shear Strength with respect to Soil Suction, Can.Geotech.J. Vol.33, 1996

[22] Matysa , E.L. , Radhakrishna.H.S., Volume Change Characteristic of Partially Saturated Soils, Geoteehnique,VOl.18, No.4, Dec. 1968,pp.432-448.

[23] Bishop A W, Donald I B.The experim ental sutdy of partly saturated soil in the triaxial apparatus[A].Proeeeding of 5th Intenrational Conference on Soil Mechnaics and Foundation Engineering[C],Paris, Franee, 1961, 1:13-21..
[24] Croney D,Coleman J D,Black W P M, The movement and distribution of water in soil in relation to highway design and performance[R].Highway Research Board,1958,Special Report No.40.

[25] Colemna J D Stress strain relation for partly sautrated soils[J].Geoteehnique, 1961, (12)4:348-350

[26] SkemPton, Pore Pressure and Suction in soil, London, 1961, 4-16 